\title{
STUDI PENGELOLAAN TENAGA PENDIDIK DALAM RANGKA IMPLEMENTASI MANAJEMEN BERBASIS SEKOLAH PADA SEKOLAH LANJUTAN TINGKAT ATAS DI KOTA PALANGKA RAYA
}

\author{
Educator Management Study In Daeng Implementation Of School-Based Management At The Top-Level \\ Advanced School In The City Of Palangka Raya
}

\section{Raden Biroum \\ Bernandianto* \\ Vivi Friskila Angela}

Universitas Muhammadiyah Palangkaraya, Palangka Raya,

Central Kalimantan, Indonesia

email: a biem@gmail.com

\begin{abstract}
Abstrak
Tujuan Penelitian ini adalah untuk mengetahui Studi Pengelolaan Tenaga Pendidik Dalam Rangka Implementasi Manajemen Berbasis Sekolah Pada Sekolah Lanjutan Tingkat Atas Di Kota Palangka Raya. Metode yang digunakan dalam penelitian ini adalah kualitatif. Sumber data primer yaitu Kepala Dinas Pendidikan Provinsi Kalimantan Tengah, Ketua Yayasan, Kepala Sekolah, Wakil Kepala Sekolah, Tenaga Pendidik, Tenaga Kependidikan, Ketua Komite Sekolah. Sumber sekunder berupa buku-buku, jurnal ilmiah, arsip dan dokumen.
\end{abstract}

Hasil penelitian Rekrutmen dan Penempatan Pendidik dimana Proses rekrutmen tenaga pendidik diawali dengan perencanaan yang matang. bahwa rekrutmen guru disesuaikan dengan kebutuhan mata pelajaran yang dilakukan pada tiap-tiap awal tahun ajaran. Perekrutan guru sebagai tenaga pendidik tidak dilakukan setiap saat, karena komposisi guru sebagai tenaga pendidik yang tetap sudah ada dan cenderung tidak berubah. Pemberian Kompensasi Sistem pemberian kompensasi yang digunakan menggunakan sistem kompensasi secara finansial/langsung dan kompensasi non finansial/tidak langsung. Sistem kompensasi secara finansial/langsung diberikan berupa gaji pokok. Sedangkan kompensasi non finansial/kompensasi tidak langsung diberikan berupa tunjangan. Pola pembinaan dan pengembangan yang terstruktur belum Nampak dilakukan oleh sekolah yang menjadi lokasi penelitian. Hasil penelitian menyimpulkan bahwa tidak terdapat aturan baku terkait pelepasan dan pemberhentian tenaga pendidik.

\section{Kata Kunci: \\ Studi \\ Pengelolaan \\ Tenaga Pendidik \\ Implementasi \\ Manajemen \\ Keywords: \\ Study \\ Management \\ Educators \\ Implementation \\ Management}

\section{Accepted \\ January 2019}

\section{Published}

April 2019

\begin{abstract}
The purpose of this research is to know the study of educators ' management in the framework of the implementation of school-based management in the high School of Palangka Raya. The method used in this study is qualitative. The primary data source is the head of Central Kalimantan Provincial Education Office, Chairman of the Foundation, school principal, deputy principal, educators, education personnel, Chairman of the School Committee. Secondary sources are books, scientific journals, archives, and documents.

Research results of recruitment and educator placements where the recruitment process of educators begins with a mature plan. That teacher recruitment is tailored to the needs of the subjects performed in each early school year. Recruitment of teachers as educators is not conducted at all times, because of the composition of teachers as educators who remain existing and tend not to change. Compensation system for compensation used using the compensation system financially/directly and nonfinanciallindirect compensation. The compensation system is financially/directly given as a basic salary. While non-financial compensation/compensation is not directly given in the form of allowances. Structured coaching and development patterns have not seen the school's research site. The results concluded that there were no raw rules relating to the release and dismissal of educators.
\end{abstract}

\section{PENDAHULUAN}

Dalam hal perencanaan pendidikan, terdapat berbagai macam aspek yang sangat penting untuk dipertimbangkan. Seperti perencanaan dari segi visi dan misi, kurikulum, lingkungan, sarpras, dan lain sebagainya. Ada satu aspek yang yang juga sangat urgensi untu dibuat perencanaannya ialah terkait tenaga pendidik dan kependidikan.

Maka dari itulah, dengan mempertimbangkan peran tenaga pendidik dan kependidikan yang sangat penting tersebut, sudah selayaknya dibuat suatu mekanisme perencanaan dan pengelolaan bagi dua 
profesi tersebut agar dapat mengembangkan kompetensi di bidang pendidikan demi peningkatan kualitas mutu pendidikan.

Ada beberapa permasalahan yang muncul berkaitan dengan pengelolaan guru, yang cenderung akan menjadi sebuah permasalahan dalam pengelolaan guru di sekolah (utamanya sekolah swasta terkait keterbatasan tenaga pendidik) diantaranya terkait kompetensi guru yang dimiliki. Berdasarkan Permendiknas No. 16 Tahun 2007, guru harus memiliki empat kompentensi, antara lain Kompetensi Padegogik, Kompentensi Keahlian, Kompentensi Sosial dan Kompentensi Profesional.

Selanjutnya dalam pendayagunaan ketenagaan kelayakan Guru mengajar menjadi sebuah persoalan lain, sehubungan bahwa kualitas guru dapat dilihat dari kualitas mengajarnya dan guru yang profesional tentu akan memperlihatkan kinerjanya dengan baik. Kinerja guru yang baik diharapkan dapat memperlancar proses pembelajaran dan berdampak terhadap prestasi belajar siswa, pelaksanaan pembagian tugas Guru, Tenaga Teknis, dan Tenaga Tata Laksana, Pemberian tugas tambahan kepada Guru, dan Tenaga Teknis yang belum memenuhi jumlah jam wajib mengajar minimal.

\section{METODOLOGI}

Metode penelitian yang di gunakan dalam penelitian ini adalah model penelitian kualitatif di mana peneliti akan melakukan penelitian dengan memulai pada beberapa fenomena-fenomena yang akan di tangkap dari lokus penelitian. Dalam pembuatan penelitian kualitatif akan di mulai dengan pencarian masalah yang di akan dijadikan rumusan masalah dalam penelitian.

Metode kualitatif berkembang mengikuti suatu dalil sebagai proses yang tidak pernah berhenti (unfinished process). la berkembang dari proses pencarian dan penangkapan makna yang diberikan oleh suatu realitas dan fenomena sosial. Penelitian ini ingin menggambarkan tentang bagaimana implementasi MBS pada pengelolaan tenaga pendidik di Sekolah Lanjutan Tingkat Atas Kota Palangka Raya.

\section{HASIL DAN PEMBAHASAN}

\section{Rekrutmen dan Penempatan Pendidik}

Proses rekrutmen tenaga pendidik diawali dengan perencanaan yang matang. bahwa rekrutmen guru disesuaikan dengan kebutuhan mata pelajaran yang dilakukan pada tiap-tiap awal tahun ajaran. Perekrutan guru sebagai tenaga pendidik tidak dilakukan setiap saat, karena komposisi guru sebagai tenaga pendidik yang tetap sudah ada dan cenderung tidak berubah.

Rekrutmen guru mengajar sebagai tenaga pendidik di SMA Negeri dilakukan oleh Kepala Sekolah beserta Wakilnya merupakan Guru honor yang dibiayai oleh dana sekolah. Rekrutmen semacam ini untuk mengisi kekosongan tenaga pendidik bagi mata pelajaran tertentu di luar Guru PNS yang sudah ada.

Pada sekolah swasta rekrutmen dilakukan tidak hanya oleh pimpinan sekolah, juga melibatkan yayasan. Hal ini diterapkan mengingat bahwa yayasan sebagai pemilik yang mengelola dan menanungi sekolah, sedangkan kepala sekolah sebagai pengelola pembelajaran dan wakil kepala sekolah membantu kepala sekolah dalam mengelola pembelajaran.

\section{Pemberian Kompensasi}

Pemberian kompensasi oleh SMA Swasta sedikit berbeda dengan yang berlaku di SMA Negeri. Pada SMA Isen Mulang dan SMK Karsa kompensasi bagi guru berdasarkan status kepegawaian dan beban mengajarnya. Untuk beberapa guru PNS baik yang diperbantukan maupun yang mengajar tidak tetap, tidak diberikan gaji tetap oleh sekolah. Hal ini juga berlaku bagi guru tidak tetap yang hanya dibayarkan berdasarkan jam mengajar saja.

Sistem pemberian kompensasi yang digunakan menggunakan sistem kompensasi secara finansial/langsung dan kompensasi non finansial/tidak 
langsung. Sistem kompensasi secara finansial/langsung diberikan berupa gaji pokok. Sedangkan kompensasi non finansial/kompensasi tidak langsung diberikan berupa tunjangan.

Penentapan gaji pokok sebagai kompensasi telah mengacu pada sistim penggajian berdasarkan golongan, jabatan dan lama waktu kerja. Gaji tersebut terdiri atas Gaji Pokok dan beberapa Tunjangan yang rutin diberikan sesuai dengan jabatan serta kinerjanya.

\section{Pembinaan dan Pengembangan}

Pola pembinaan dan pengembangan yang terstruktur belum Nampak dilakukan oleh sekolah yang menjadi lokasi penelitian ini. Keinginan yang kuat tersirat, namun dari hasil kajian dokumen yang dilakukan penulis belum menemukan "disain pengembangan" yang terencana dengan sistimatik. Namun bukti di lapangan menunjukan telah dilakukan pembinaan dan pengembangan baik yang dilakukan secara eksternal, seperti kegiatan pelatihan oleh dinas terkait, dan juga yang bersifat pembinaan internal oleh Kepala Sekolah dan atau guru senior.

\section{Pelepasan/Pemberhentian}

Hasil penelitian menyimpulkan bahwa tidak terdapat aturan baku terkait pelepasan dan pemberhentian tenaga pendidik. Pengaturan secara umum bagi pegawai yang memuat sanksi berupa pemberhentian apabila tidak disiplin dan melakukan perbuatan kriminal serta asusila teradapat di sekolah swasta tempat penelitian ini dilakukan.

\section{KESIMPULAN}

I. Perekrutan dan Penempatan Tenaga Pendidik

Perekrutan pendidik pendidik dilaksanakan dengan sistem yang berlaku umum serta bersifat informal dan belum memiliki panduan khusus. Pengelola sekolah swasta hanya melakukan musyawarah untuk menentukan individu-individu yang layak untuk direkrut menjadi pendidik dan menempatkan individu yang tepat pada posisi/jabatan yang juga tepat (the right man on the right place). Pengelola sekolah negeri mengikuti prosedur perekrutan PNS secara umum.

2. Pemberian Kompensasi bagi Tenaga Pendidik

Pemberian kompensasi terhadap tenaga pendidik oleh SMA Swasta berbeda dengan di SMA Negeri. Kompensasi bagi guru swasta berdasarkan status kepegawaian dan beban mengajarnya, untuk beberapa guru PNS baik yang diperbantukan maupun yang mengajar tidak tetap tidak diberikan gaji tetap oleh sekolah. Hal ini juga berlaku bagi guru tidak tetap yang hanya dibayarkan berdasarkan jam mengajar saja.

3. Pembinaan dan Pengembangan Pendidik

Pola pembinaan dan pengembangan yang terstruktur belum nampak dilakukan. Disain pengembangan yang terencana dengan sistimatik belum dikembangkan. Pembinaan dan pengembangan dilakukan secara eksternal, seperti kegiatan pelatihan oleh dinas terkait, dan juga yang bersifat pembinaan internal oleh Kepala Sekolah dan atau guru senior. Tujuan mereka adalah untuk memastikan bahwa sekolah memperkerjakan keseimbangan tenaga pendidik yang tepat dalam hal keterampilan dan pengalaman, dan bahwa kesempatan pelatihan dan pengembangan yang tersedia bagi tenaga untuk meningkatkan kinerja mereka dan mencapai tujuan organisasi.

4. Pelepasan atau Pemberhentian Pendidik

Pelepasan/pemberhentian tenaga pendidik dilaksanakan apabila pihak pendidi mengajukan pengunduran diri kepada pihak pengelola. Pengelola tidak menetapkan aturan baku mengenai pelepasan atau pemberhentian pendidik, seperti criteria-kriteria pendidik yang harus diberhentikan. 


\section{REFERENSI}

Arikunto, Suharsimi. 2003. Prosedur Penelitian Suatu Pendekatan Praktik. Jakarta: Bina Aksara.

David, R. Fred. 2004. Konsep Manajemen Strategis, Edisi VII (terjemahan). Jakarta, PT Indeks.

Fattah, Nanang. 2004. Konsep Manajemen Berbasis Sekolah dan Dewan Sekolah. Bandung: CV Pustaka Bani Quraisy.

Ibnu Hajar A, Aan Komariah, dan Dedy Achmad K. “Implementasi Manajemen Berbasis Sekolah dalam Upaya Meningkatkan Mutu Sekolah (Studi Analisis Deskriptif Implementasi manajemen Berbasis Sekolah di SMAN 2 Indramayu". Jurnal Administrasi Pendidikan. Vol. I Nomor I. 2014. HIm : 3.

Ismail, M. Yusanto. 2003. Pengantar Manajemen Syariat, Cetakan II. Jakarta. Khairul Bayan.

Murniati. 2008. Manajemen Stratejik. Peran Kepala Sekolah Dalam Pemberdayaan. Bandung: Citapustaka Media Perintis.

Rosmalah. "Hakikat Implementasi Manajemen Berbasis Sekolah". Jurnal Publikasi Pendidikan. Vol. VI Nomor I. 2016. HIm : 66.

Sagala, Syaiful. 2006. Manajemen Berbasis Sekolah dan Masyarakat: Strategi Memenangkan Persaingan Mutu. Jakarta. PT Nimas Multima.

Suparlan. 20I3. Manajemen Berbasis Sekolah dari Teori sampai dengan Praktik. Jakarta: Bumi Aksara.

Syafaruddin. 2005. Manajemen Lembaga Pendidikan Islam, Cetakan I. Jakarta: Ciputat Press.

Wirio, Soebagio. 2000. Manajemen Pendidikan Indonesia. Jakarta: PT. Ardazya Jaya.

\section{Perundang-Undangan}

Departemen Pendidikan Nasional. 2003. UndangUndang RI Nomor 20 Tahun 2003 Tentang Sistem Pendidikan Nasional. Dicetak oleh Biro Hukum dan Organisasi Sekretriat Jenderal Depdiknas.
Departemen Pendidikan Nasional. 2005. Peraturan Menteri pendidikan Pendidikan Nasional Nomor 16 Tahun 2003 Tentang Kompetensi Guru.

Departemen Pendidikan Nasional. 2005. Peraturan Pemerintah Nomor 19 Tahun 2005 Tentang Pelaksanaan Manajemen Berbasis Sekolah 